\title{
EFFECT OF CIRCULAR OPENINGS ON WEB CRIPPLING OF UNLIPPED CHANNEL SECTIONS UNDER END-TWO-FLANGE LOAD CASE
}

\author{
Elilarasi. K, Kasthuri. S and Janarthanan. B *
}

Department of Civil Engineering, Faculty of Engineering, University of Jaffna, Sri Lanka

*(Corresponding author: E-mail: $\underline{\text { Jana151188@eng.ifn.ac.lk) }}$

\begin{abstract}
A B S T RACT
Cold-formed steel unlipped channels with web openings increasingly employed as bearers and joists in the floor systems to embed the building services to maintain adequate clear storey-height and aesthetic appearance. The use of thin-unlipped channels is limited in the past due to flange buckling and mostly web crippling behaviour of lipped channels with web openings was investigated. However, with the thickness increment, the flange buckling of unlipped channels is limited, and these sections are used widely in construction. The major drawback with these cold-formed steel profiles is web crippling, localized failure due to higher web slenderness ratio. Web openings reduce the carrying web area of the sections, hence makes the unlipped channels more vulnerable to web crippling. Currently, unlipped channels with web openings are increasingly employed, although no proper guidelines are available to determine the capacity reductions due to the introduction of web openings. The main cold-formed steel specifications such as North American Specification (AISI S100) and Australian/ New Zealand standard (AS/NZS 4600) employ the unified design equation with different coefficients for all four load cases while Eurocode 3 Part 1-3 (ECS) employs different equations for each load case. In these specifications, design guidelines are available only for offset web openings for unlipped channels under one-flange load cases. This study investigates the effects of circular centred beneath and offset web openings on the capacity reduction of unfastened support unlipped channels subject to web crippling under end two flange load cases. The suitable reduction factor equations have been proposed for circular web openings of unlipped channels located directly underneath and away for the bearing plate using the outcome form the numerical study.
\end{abstract}

\begin{tabular}{ll} 
A R T I C L E & H I S T O R Y \\
\hline Received: & 6 March 2020 \\
Revised: & 23 June 2020 \\
Accepted: & 27 July 2020
\end{tabular}

\section{K E Y W O R D S}

Web crippling,

Cold-formed steel,

Unlipped channels,

Finite element analysis,

End-Two-Flange (ETF)

Web openings.

\section{Introduction}

Cold-formed steel portrays benefits such as the enhanced strength to weight ratio, fabrication easy and accurate in dimensions, compared to hot-rolled steel. The thickness of cold-formed steel profiles has been limited to $3.00 \mathrm{~mm}$ due to limitations in manufacturing technology in the past. Channel profiles such as lipped and unlipped are commonly employed in the building industry among different available shapes of cold-formed steel profiles. The lipped channels are more employed as joists and bearers in the typical floor systems due to their better performance under flexure compared to unlipped channels, where later may experience the buckling at compression flange under flexure. The thickness of cold-formed steel profiles is improved up to $8.00 \mathrm{~mm}$ due to advancement in the manufacturing technology. The thickness improvement reduces the possibilities of flange buckling of unlipped channels, and hence the usage of unlipped channels also increased similar to lipped channel profiles. Web crippling is a crucial localised problem, especially at the point loads and reactions in this cold-formed steel profiles because of higher web slenderness ratios due to small thicknesses. New building constructions employ these unlipped steel channels with circular openings at their webs to accommodate building services within the floor system to ensure aesthetic appearance and to maintain the clearance storey-height. However, the removal of the circular web part from the unlipped channel reduces the carrying area of the point loads and reactions and makes the profile more critical under web crippling. The behaviour of lipped channels under web crippling has been investigated without [1-5] and with the opening [6-17] at its webs, which is different from the performance of unlipped channels. However, the behaviour of unlipped channels with an opening has not explored in the past. Therefore, the web crippling performance of unlipped channels with circular openings at the web should be investigated thoroughly due to its increase in usage.

In addition to the conventional parameters such as different load cases, steel profiles and support conditions, the ultimate failure load of steel profiles with web opening depends on types and diameter of the web opening. As per existing cold-formed steel codes such as North American Specification (AISI S100) [18], Australian/ New Zealand Standard (AS/NZS 4600) [19] and Eurocode 3 Part 13 (ECS) [20] classified the practical failure modes into four as shown in Fig. 1 such as (i) End-One-Flange (EOF) (ii) End-Two-Flange (ETF) (iii) InteriorOne-Flange (IOF) and (iv) Interior-Two-Flange (ITF) load cases based on their distances between loading and support reactions and failure locations while support conditions are unfastened and fastened conditions. Openings at the webs of the profiles are also commonly classified into two groups in the past studies as shown in Fig. 2 such as (i) centred beneath web opening, where the opening is located directly underneath the loading plate (ii) offset web opening where the opening is placed away from the bearing plate. Usually, the performance of cold-formed steel under web crippling is being investigated experimentally due to complexities involved in the theoretical methods. However, experimental studies are expensive and require more material. Hence the new approach of using numerical analysis which was introduced by Sivakumarn [22] with proper validations, is followed in this study. Finally, this study carefully investigates the reduction in the failure capacity of unlipped channels with a circular opening at the web of the profiles under web crippling with unfastened supports under ETF load case based on adequately developed and validated numerical models.

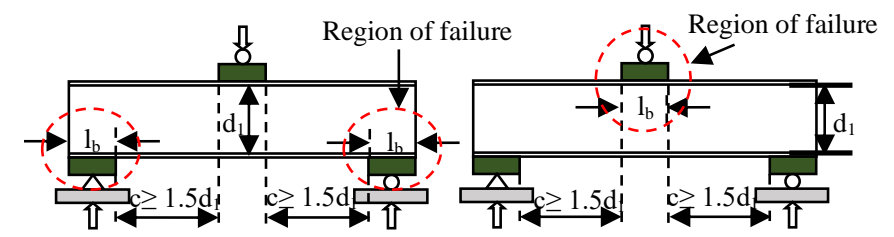

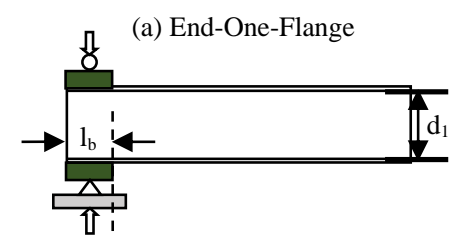

(c) End-Two-Flange

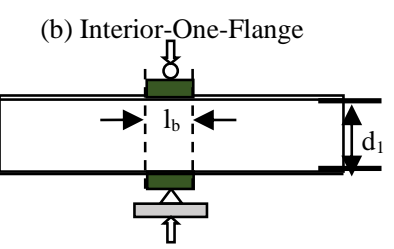

(d) Interior-Two-Flange
Fig. 1 Web crippling load cases [21]

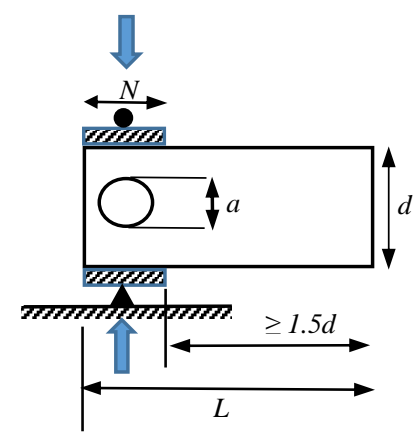

(a) Centered beneath web opening

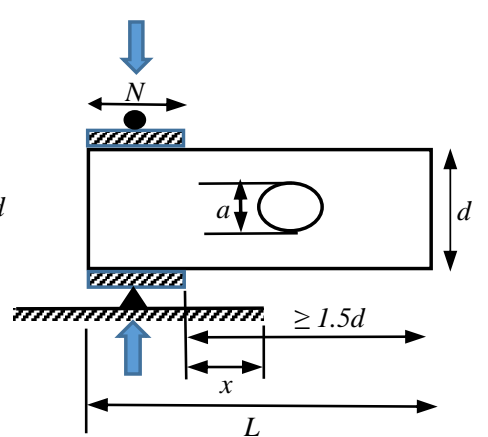

(b) Offset web opening
Fig. 2 ETF loading condition with centred beneath and offset web opening

Among available primary three cold-formed steel standards, AISI S100 [18] and AS/NZS 4600 [19] employ the unified web crippling design equation which is shown by Equation 1 to determine ultimate failure loads of various steel profiles subjected to web crippling. As shown, the particular equation is developed based on different ratios such as: bearing length to thickness $\left(\mathrm{l}_{\mathrm{b}} / \mathrm{t}\right)$, 
web slenderness $\left(d_{1} / t\right)$ and inside bent to thickness $\left(r_{i} / t\right)$ in addition to material yield strength $\left(\mathrm{f}_{\mathrm{y}}\right)$ and section thickness (t). Particular equation covered all four load cases and fastened/unfastened supports with only differing values of four coefficients. Eurocode 3 Part 1 [20], totally different from the two standards mentioned above, employs different equations for each load case without separating support conditions, as shown in Equations $2 \& 3$.

$\mathrm{R}_{\mathrm{b}}=\mathrm{Ct}^{2} \mathrm{f}_{\mathrm{y}} \sin \theta\left(1-\mathrm{C}_{\mathrm{r}} \sqrt{\frac{r_{i}}{t}}\right)\left(1+C_{1} \sqrt{\frac{l_{b}}{t}}\right)\left(1-C_{w} \sqrt{\frac{d_{1}}{t}}\right)$

For the ETF load case:

$R_{b}=k_{1} k_{2} k_{3}\left[6.66-\frac{h_{w}}{64 t}\right]\left[1+0.01 \frac{l_{b}}{t}\right]^{2} f_{y} / \gamma_{M 1}$

For the ITF load case:

$R_{b}=k_{3} k_{4} k_{5}\left[21.0-\frac{h_{w}}{16.3 t}\right]\left[1+0.0013 \frac{l}{t}\right] t^{2} f_{y} / \gamma_{M 1}$

where: $k_{1}, k_{4}$ : coefficients for the strength of the material, $k_{2}, k_{5}$ : coefficients for the inside bend radius to the thickness ratio, $\mathrm{k}_{3}$ : coefficients for the angle between the flange and web, $\mathrm{h}_{\mathrm{w}}$ : web height between flange mid-lines, $\gamma_{\mathrm{M} 1}$ : partial safety factor. Other notations are similar to Equation 1.

Although steel profiles with web openings used in building construction, there are only a few guidelines available in main cold-formed steel specifications such as AISI S100 [18] and AS/NZS 4600 [19] to calculate the capacity reduction of web crippling due to web openings. The available guideline is also limited to offset web openings for unlipped channels subject to interior one flange load cases as shown by Equations (4a) and (4b), where $d, h$, and $x$ are the diameter of the web opening, depth of a straight portion of the web of unlipped channels and closest distance to web opening from the bearing plate. Unlipped channels with higher thicknesses are used in floor systems as bearers with web openings nowadays more often, especially with circular web openings. However, there have been no investigations performed to determine the reduction of the web crippling of unlipped channels with circular web openings. Hence, it is addressed in this study by numerical analysis. The effects of both types of web openings such as centred beneath and offset have been investigated for unlipped channels with unfastened supports under the load case of End-TwoFlange.

$R=1.01-0.325 d / h^{+0.083 x} / h^{\leq 1.0}$

$R=0.90-0.047 d / h+0.053 x / h \leq 1.0$

\section{Literature review}

The behaviour of cold-formed steel profiles subjected to web crippling failure have been investigated since the 1940s with the experimental studies performed by Winter and Pian [23], hence have a long history. These past studies have been critically analysed and discussed in this section into mainly two groups such as (i) experimental investigations of steel profiles without and with the presence of web openings and then (ii) numerical studies of steel profiles without and with the presence web openings.

1a: Firstly, web crippling performance of cold-formed I-sections were explored by Winter and Pian [23] using 136 tests and empirical design equations were developed. Hetrakul and Yu [1] investigated the performance of lipped and unlipped channels subjected to web crippling, and they noticed the capacity is slightly higher (about 10\%) for lipped channels compared to similar unlipped channels. However, they did not consider this capacity enhancement and proposed design equation commonly for channel profiles. Gerges and Schuster [2] explored the performance of lipped channels with the ratio large inside bent radius changing from 5 to 10 , subjected to web crippling with fastened supports. Beshara and Schuster [3] reported that the ultimate capacity of cold-formed steel profiles under web crippling depends on the specimen length, 50\% and 5\% higher for ITF and ETF load cases for long specimen compared to short lengths, based on a pilot study, respectively. The above-researchers [3] proposed standard specimen lengths such as $3 d$ and $5 d$, respectively for ETF and ITF load cases, where $d$ is the straight web portion of the profiles. The suggestion by the above researchers has been included in the guidelines of AISI web crippling test method [21]. Research studies mentioned above targeted the behaviour of lipped channels under web crippling while recently only, more research studies have been performed to investigate the behaviour of unlipped channels. Young and Hancock [24] and Gunalan and Mahendran [25, 26] investigated the performance of unlipped channels with unfastened supports subjected to web crippling under all four load cases. Based on their study above researcher [2426] informed that predicted values of unified design equation with existing coefficients were unconservative for unlipped channels with unfastened support condition. Therefore Young and Hancock [24] developed a design equation which is partly based on the theoretical background, yield line theory, only applicable for thick (stocky) unlipped channels for all load cases. Gunalan and Mahendran [25,26] stayed with the unified design equation format but with new proposed coefficients by them for all load cases. Sundararajah et al. [5, 27] proved that the structural performance of lipped and unlipped channels are different, and they separately proposed coefficients to the unified design equation as listed in Table 1. Janarthanan et al. [28-31] identified that AISI S100 [18] still have shortcomings, such as no coefficients available to determine the web crippling capacity of unlipped channels with fastened supports under one flange load cases. They have proposed coefficients to the unified design equation based on experimental and numerical investigations. These show there are certain shortcomings in the current North American Specification (AISI S100) [18] and Australian/New Zealand standard (AS/NZS 4600) [19].

Table 1

Proposed coefficients to web crippling unified design equation $[5,27]$

\begin{tabular}{llllll}
\hline Equation & Load case & C & $\mathrm{C}_{\mathrm{r}}$ & $\mathrm{C}_{1}$ & $\mathrm{C}_{\mathrm{w}}$ \\
\hline \multirow{4}{*}{ Proposed for Lipped channels } & ETF & 5.35 & 0.22 & 0.23 & 0.06 \\
& ITF & 17.0 & 0.19 & 0.05 & 0.03 \\
& EOF & 6.3 & 0.1 & 0.10 & 0.02 \\
& IOF & 4.9 & 0.01 & 0.38 & 0.03 \\
& ETF & 3.60 & 0.15 & 0.15 & 0.05 \\
Proposed for Unlipped channels & ITF & 15.6 & 0.25 & 0.01 & 0.001 \\
& EOF & 9.0 & 0.30 & 0.20 & 0.05 \\
& IOF & 14.7 & 0.18 & 0.05 & 0.01 \\
\hline
\end{tabular}

Note: EOF, IOF, ETF and ITF: End-One, Interior-One, End-Two and Interior-Two-Flange load cases, $\mathrm{C}_{\mathrm{r}}, \mathrm{C}_{\mathrm{l}}, \mathrm{C}_{\mathrm{w}}$ - coefficient values ratios for the corner radius to thickness, bearing length to thickness, web slenderness and $\mathrm{C}$ is a general coefficient

1b: The cost-effective way of investigating the behaviour of cod-formed steel subject to web crippling is using numerical analysis. Lots of finite element software are available nowadays, among that commonly used software in the investigation of web crippling are ANSYS, ABAQUS and ADINA. These softwares mentioned above are used for parametric study and to enhance the data strength after proper model validation. Considering recent numerical studies, McDonald et al. [4] developed numerical models for lipped channels using ANSYS for all four load cases and validated the developed models using their test results. Ren et al. [32] also used ANSYS and validated their developed FE models using already existed test data of web crippling of Young and Hancock [24]. Similarly, Natario et al. [33], Sundararajah et al. [5], and Janarthanan et al. [29, 31] developed FE models in ABAQUS and validated their FE models using quasi-static analysis by explicit analysis. As discussed above, the crucial part of finite element analysis is accurate validation.

2a: Similar to steel profiles without web opening, the effect of web openings on the web crippling capacity of the lipped channel is investigated mostly in the past, compared to unlipped channels. In all past studies [7-9], the web openings are classified into main two types such as (i) centred beneath and (ii) offset web openings as shown in Fig. 2, wherein the first type, the web opening is directly placed underneath the bearing plate while in the second type, the web opening is placed away from the bearing plate. First, $\mathrm{Yu}$ and Davis [6] investigated the performance of lipped channels under web crippling with two different opening shapes such as (i) circular and (ii) square, located directly underneath the bearing plate under IOF load case based on 20 results. Sivakumaran and Zielonka [7] performed an experimental study to find the effect of different shapes of web openings on the web crippling capacity of lipped channels with unfastened supports using 103 test results. The above researchers [7] observed that then design equations were unconservative for lipped channels with web openings. Hence they proposed a reduction factor equation for lipped channels using two ratios such as (i) opening height to a depth of a straight portion of the web $(a / h)$ and (ii) opening width to effective bearing length $\left(b / n_{1}\right)$. Langan et al. [8] explored web crippling behaviour of lipped channels with a rectangular opening under one flange load cases (both EOF and IOF) using 78 and 90 tests, respectively and they proposed reduction 
factors separately for load cases.

LaBoube et al. [9] explored the behaviour of lipped channels with circular web openings subjected to web crippling for EOF and IOF load case based on their 56 and 52 tests, respectively. They developed an equation for capacity reduction for lipped channels based on two ratios such as the ratio of web opening distance from the edge of the bearing plate $(x / h)$ and bearing length to the height of the straight portion of the web $(N / h)$. However, the critical limitation in the outcome of the study is that the thicknesses of the profiles used ranged between $0.83 \mathrm{~mm}$ to $1.42 \mathrm{~mm}$. These developed equations by LaBoube et al. [9] are included in AISI S100 [18] and AS/NZS 4600 [19] standards and still used to calculate the web crippling capacities of lipped channels with web openings. As mentioned above, the limitation raises the question of the applicability of these equations to thick-lipped channels, which are mostly used in current building construction. There are no other design guidelines available in any cold-formed steel specifications to determine web crippling failure loads of cold-formed steel profiles with web openings.

2b: Recently Uzzaman et al. [10-13] investigated the performance of lipped channels with circular web openings (i) located directly underneath and (ii) located away from the bearing plates, subjected to web crippling for two-flange load cases using experimentally and numerically. They have only modelled half of the profiles considering symmetric boundary conditions shown in Fig. 3 in ANSYS software to make their FE models time effective. Boundary conditions were only applied to the modelled loading plates and then transferred to flanges of the beam via contacts. Two support conditions, such as unfastened and fastened, were considered during their investigation. After proper validation and then parametric studies, they identified two critical ratios affects the web crippling capacity of lipped channels with web openings placed directly beneath the bearing plate such as the ratio of the diameter of the web opening to the straight portion of the web $(a / h)$ and the ratio of bearing length to the height of the straight part of the web $(N / h)$. Similarly, another two critical ratios were identified for web openings placed away from the bearing plate such as the ratio of the web opening distance from the bearing plate to the height of the straight portion of the web $(x / h)$ and bearing length to the height of the straight portion of the web $(N / h)$. The two separate reduction factor equations were proposed for unlipped channels with web openings located directly underneath and away from bearing plates using above-identified critical ratios. Based on their observation, the capacity reduction percentages improved from 40 to 35 and 50 to 40 for lipped channels with the circular centred beneath web opening with its size equal to 0.8 times the height of straight part of the web, under ITF and ETF load cases, respectively when supports were converted to fastened from the unfasted condition. Similarly, the capacity increased from 20 to 25 and 30 to 35 percentage for unlipped channels with web openings located away from the bearing plate for ITF and ETF load cases, respectively for the web openings placed with the distance of 0.8 times the height of the straight part of the web when supports were changed to a fastened case from unfastened supports.

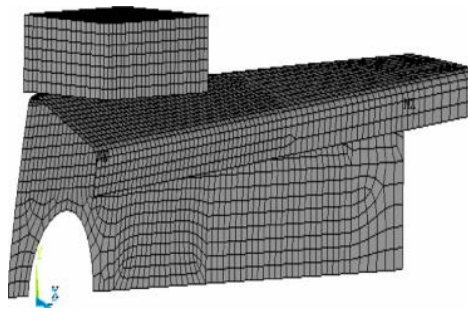

(a) Centered beneath web hole

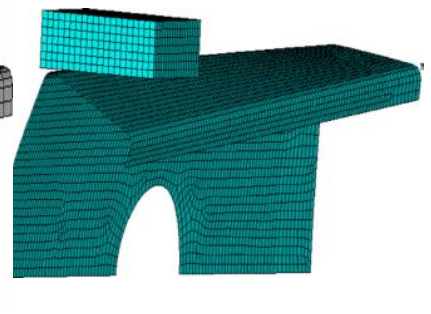

(b) Offset web hole
Fig. 3 Half FE models in ANSYS [10- 13]

Lian et al. [14-17] investigated the effect of both types of circular web openings, openings located underneath and away from the bearing plates on the capacity of unlipped channels subject to web crippling under one flange load cases. They first performed a limited number of experimental studies then performed numerical analysis using ABAQUS/CAE software. Above researchers [14-17] reported that the capacity reduction of unfastened support lipped channels with circular web opening placed directly underneath the bearing plate is about 10 and 12 percentages for EOF and IOF load cases when the ratio of the diameter of the web opening to the height of straight part of the web $(a / h)$ is varied from 0 to 0.6 . However, capacity reduction percentages are less than $5 \%$ for unlipped channels with web openings with fastened supports for both EOF and IOF load cases for the above-mention ratio with the same value range. The comparison of Uzzaman et al. [10-13] and Lian et al. [14-17] showed that the capacity reduction is more significant for lipped channels subjected to web crippling under two flange load case compared to one flange load case. Therefore, the behaviour of unlipped channel profiles under twoflange load cases also should be investigated for conservative design. Recently, Elilarasi and Janarthanan [34] investigated the behaviour of unfastened supports rectangular hollow flange beams (LSBs) with a circular web centred beneath and offset openings subject to web crippling using numerical analysis in ANSYS after accurate validation. They proposed two separate capacity reduction factor equations for LSBs with web openings located directly underneath and away from the bearing plates, respectively, after identifying the critical ratios.

In past experimental investigations, the different test set-ups and specimen lengths were used and created inconsistent between investigations. Three different test specimen arrangements such as (i) two mono-symmetric profiles facing each other to form a box arrangement [1, 25-28] (ii) two mono-symmetric profiles placed back to back [24] and (iii) single section only [4] for one flange load cases were employed. In addition, different specimen lengths were used especially under two flange load case such as (i) 1.5 times the height of the straight part of the web plus bearing length [24], (ii) 400 and $600 \mathrm{~mm}$ specimen lengths for ETF and ITF respectively [4] and (iii) three and five times overall depth of the sections for ETF and ITF respectively [3, 25-27]. AISI web crippling standard test method [21] is updated, which gives the proper guidelines about the specimen lengths and test set-up arrangement, should be followed in all experimental and numerical investigations about web crippling to prevent discrepancies in the selection of specimen lengths and test set-ups.

The discussion in the above section indicates that the structural performance of lipped and unlipped channels subject to web crippling is different under all four load cases. The recent research studies proposed new coefficients to the unified design equation to predict the capacity of unlipped channels subject to web crippling with fastened and unfastened supports. However, the main research gap is, although these steel profiles are increasingly used with web openings in the floor system, still, there have been no research studies performed to investigate the capacity reduction due to web openings on the web crippling capacity of unfastened unlipped channels under all four load cases. The effective approach to investigate this problem is utilizing the advancement in the computer technology, accurate finite element model development with the help of existing experimental data and then use the develop numerical models to investigate the capacity reduction of unlipped channels with web openings under web crippling. This journal paper addresses the reduction in the web crippling capacity of unlipped channel sections with unfastened supports due to the centred beneath and offset web openings under End-Two-Flange load case.

\section{Research approach}

The capacity reduction of unfastened support unlipped channels with web openings subject to web crippling under ETF load case is investigated using numerical analysis based on the given research approach as shown in Fig. 4 in this study. Five different existing web crippling data such as Sundararajah et al. [5, 27], Young and Hancock [24] and Uzzaman et al. [11-13] were used for this validation purpose.

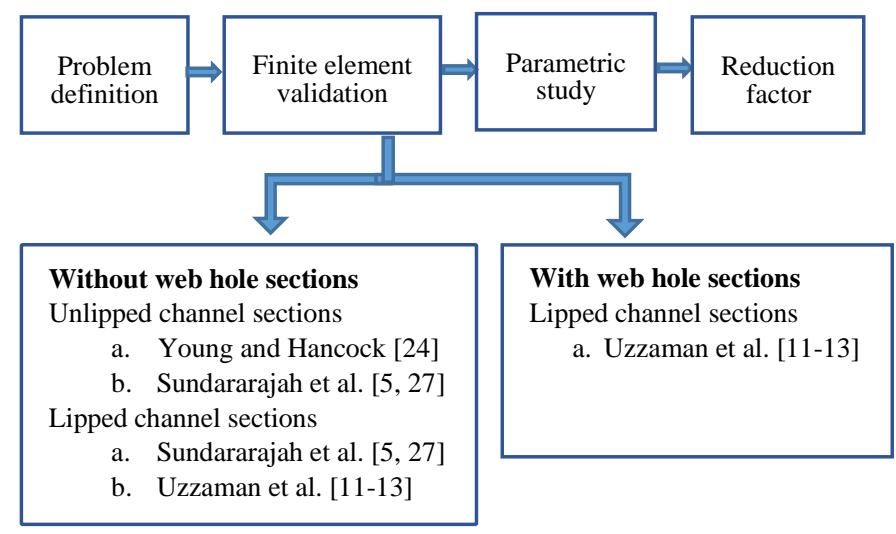

Fig. 4 Research approach

In the above studies, Sundararajah et al. $[5,27]$ explored the behaviour of thin-lipped and unlipped channels under web crippling where the overall depth of considered steel profiles varied from 100 to $200 \mathrm{~mm}$ while their thicknesses varied from $1.0 \mathrm{~mm}$ to $2.4 \mathrm{~mm}$. Their specimen length is $3 d$, where $d$ is the 
height of straight part of the web of the sections, and three bearing lengths were used in their studies. Since Sundararajah et al. [5, 27] experimental study was limited to thin-sections, Young and Hancock [24] test results also used to validate the developed FE models to ensure the accuracy of models for both thin and thick steel profiles. Young and Hancock's [24] tests used thick unlipped channels with an overall depth of 75 to $300 \mathrm{~mm}$ while the thicknesses varied from 3.8 to 6.0. Their specimen lengths are equal to 1.5 times overall height of unlipped channel sections plus bearing length, and their bearing lengths were chosen equal to half and the full width of flanges. Uzzaman et al. [11-13] investigated the effect of web openings, both placed underneath and away from the bearing plates on the web crippling capacity of lipped channels using experimentally and numerically for two flange load cases. The overall depth varied from 142 to $302 \mathrm{~mm}$ while thicknesses ranged from 1.3 to $2.0 \mathrm{~mm}$. They used three bearing lengths such as 90,120 and $150 \mathrm{~mm}$ while the ratio of the diameter of circular web opening to the height of the straight part of the web is varied from 0 to 0.8 for centred beneath web openings. Their specimen length is similar to Young and Hancock [24]. The specimen lengths used by Young and Hancock [24] and Uzzaman et al. [11-13] are different compared to guidelines given in the recently updated AISI web crippling standard test method [21] while Sundararajah et al. [5, 27]'s specimen lengths are agreeing with the guidelines, which suggested to use three times the straight portion of web height of the channel sections. Although specimen length varied in above mentioned all three studies, the boundary and loadig conditions of loading and supporting plates are similar in all three tests and hence used for the validation purpose.

After accurate validation, the developed numerical model is used to enhance the data strength of unlipped channels subject to web crippling and to identify the critical parameters affecting the reduction of unlipped channels subject to web crippling. The comparison of FE capacities of unlipped channels without and with web openings are used to determine the effects of the critical parameters on the capacity reduction and to propose reduction factor equation.

\section{Numerical analysis}

Cold-formed steel profiles are thin with a thickness of less than $8.0 \mathrm{~mm}$. Hence thickness can be neglected compared to the other two dimensions. Therefore, cold-formed steel profiles, both lipped and unlipped, are simulated in ANSYS [35] as shell element models. The FE models are generated according to the measured centre line dimensions, and measured thickness is assigned to them. The prediction accuracy of finite element models depends on several factors such as (i) element type (ii) mesh size (iii) material models (iv) boundary conditions (v) contact formulation and (vi) analysis type, and importance of each factor are discussed below.

a) Element type: ANSYS [35] has different elements types such as plane, shell and solid. The behaviour of cold-formed steel profiles under web crippling can be accurately simulated using three-dimensional shell elements such as SHELL43, SHELL63, SHELL93, SHELL181 and SHELL281. In abovementioned shell elements, the first four elements are four-node elements while SHELL 281 is an eight-node element, where each node of the elements abovementioned has six degrees of freedom. However, SHELL43 is used for plastic strain, while SHELL63 and SHELL93 are used for elastic strain only. SHELL181 and SHELL281 are finite strain elements and suitable to be used in web crippling problems. The predictions of web crippling finite element models using SHELL181 and SHELL281 are the same based on the preliminary investigations. However, the FE models with SHELL281 required more computational time and resources due to its eight nodes compared to FE models with SHELL181. Therefore, SHELL181 elements were employed to model the deformable beam in the developed FE models, similar to Ren et al.'s [32] and MacDonald et al.'s [4] studies. Bearing and loading plates are also modelled using SHELL181 elements and then converted to rigid elements using rigid elements.

b) Mesh size: Mesh sizes also equally impact the prediction accuracy of web crippling capacity of generated FE models. In FE models, $3 \mathrm{~mm} \times 3 \mathrm{~mm}$ square meshes were employed for all channel sections except at the corners while fine meshes $3 \mathrm{~mm} \times 1 \mathrm{~mm}$ were employed at the corners of unlipped channel profile to ensure proper load transfer from flanges to webs of the sections

c) Mechanical properties: Since web crippling failure occurs at a yield strength of the steel, Young's modulus and material yield strengths are two material properties influence the web crippling capacity of cold-formed steel profiles. In these models, Young's modulus value of $203 \mathrm{GPa}$ with measured material yield strengths were inserted into ANSYS software. Material yield strength can be defined using two methods such as (i) engineering stress vs engineering strain and (ii) true stress vs true strain values, where the later method considers the strain hardening effects of tensile coupon specimen. The measured engineering stress-strain values can be converted to true stress-strain using the below equations (Equations. 5a and 5b). Web crippling happens at the material yield strength, not at tensile strength. Hence the impact of strain hardening effects on the web crippling failure load is minimal (maximum of $2 \%$ ) and can be neglected. Janarthanan et al. [29, 31] also reported that strain hardening effects on the web crippling are small. Hence, the bi-linear material model can be used in web crippling FE models.

$\sigma_{\text {true }}=\sigma(1+\varepsilon)$

$\varepsilon_{\text {true }}=\ln (1+\varepsilon)$

d) Loading and boundary conditions: In the developed FE models, loading and boundary conditions are only applied to the pilot node of bearing plates and then passed to the flanges of the cold-formed steel channels using interaction/ contacts only. Hence, contact/ interaction behaviour also equally contribute to the accuracy of FE models similar to boundary conditions. Contact formulation in FE models automatically considers the thickness of deformable shell elements. In the web crippling model, specimens were created using centre line dimensions. Therefore, the gap between the loading and support plates and deformable shell beams should be equal to half of the specimen thickness. Three types of contact generations are available such as pair-based contact, general contact and node to node contact. Both pair-based and general contact use surfaces to define contact and suitable for solving small or large sliding problems while node to node contact used in well-known contact locations and suitable for small sliding problems. In the developed FE models, the pair-based surface to surface contact option was used to form a contact between bearing plates and cold-formed steel sections. The penetration behaviour between rigid plates and cold-formed steel profile is decided by pressure-over closure relationship. There are two types available such as hard contact and soft contact. In these FE models, hard contact was employed in which infinity pressure is applied when both surfaces come in to contact.

The pilot node is created at mid-point of the bearing length and connected to mid-line of support and loading plates using TARGET170 element, which constraints all six degrees of freedom (three translational and three rotational degrees about $\mathrm{x}, \mathrm{y}$ and $\mathrm{z}$ axes). The boundary and loading conditions are applied to the pilot node, as displayed in Fig. 5, which is located in the centre line of the bearing plate. Two translation degrees of freedom (UX and UZ) and two rotational degrees of freedom (ROTY and ROTZ) were fixed for support and loading plates. The vertical translation was fixed (UY) for support plates, while the displacement value of $-40 \mathrm{~mm}$ was assigned to the loading plate. The loading rate was carefully controlled using a displacement controlled method. ROTX was allowed for both loading and support plates to simulate hinge supports similar to web crippling test set-up.

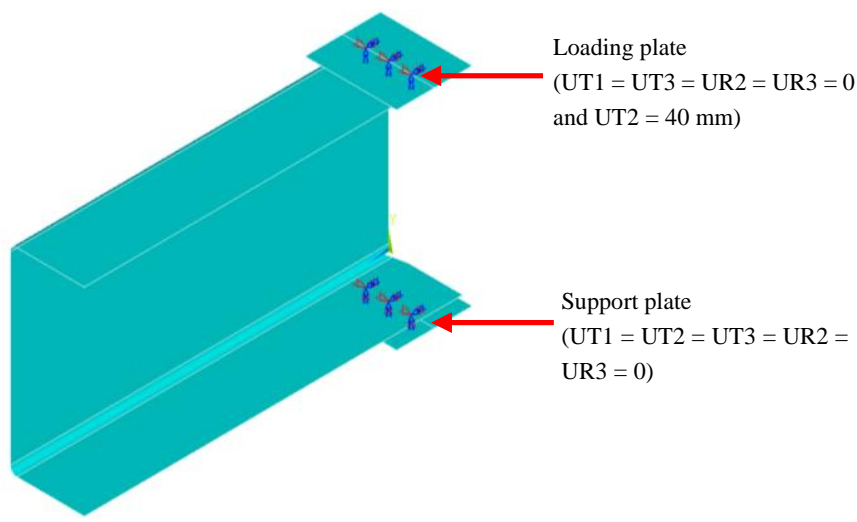

Fig. 5 Stimulation of the boundary condition

UT-Translation, UR-Rotation and 1, 2 and 3 denote the global axes $\mathrm{x}, \mathrm{y}$ and $\mathrm{z}$ respectively.

e) Analysis method: In web crippling tests, displacement control method with the displacement rate of $1 \mathrm{~mm} /$ minute was used to apply load. Hence this is a static problem. Among various analysis methods available in ANSYS [35], the static analysis was chosen in the FE study, which is related to time. The static analysis classifies large strain and small strain options. Cold-formed steel profiles experienced large strains when they were subjected to web crippling. 
Addition to that, the web crippling strength of the channels were underestimated slightly by using small strain analysis and the large strain analysis provided a better prediction. So, large displacement static was used in this study.

\section{Finite element validation \& Parametric study}

Five experimental datasets of web crippling performed by different researchers were used for the accurate FE validation purpose, as shown in Fig. 4. First, (i) Sundararajah et al. [5, 27], (ii) Young and Hancock [24] and (iii) Uzzaman et al. [11-13] test datasets were used to validate the developed FE models of channel sections, both lipped and unlipped profiles in the absence of web openings. For the validation purpose, the ultimate failure loads and failure modes obtained from numerical analysis were compared with test results. Figs. 6 and 7 show the comparison of ultimate failure loads obtained from FE models with Sundararajah et al.'s [5, 27] experimental results of lipped and unlipped channels, respectively. The comparison showed that the developed FE models of lipped and unlipped channels predicted web crippling capacities of the tested specimens accurately with the mean values of ratios of Sundararajah et al.'s [5, 27] tests to FEA predictions are 1.00 and 0.98 , respectively while corresponding $\mathrm{COV}$ values of 0.09 and 0.03 . In addition to web crippling capacity, web crippling failure mode of FE model is also compared with their experimental failure mode, as shown in Fig. 8. It can be seen that the FE model predicted the experimental failure mode accurately. However, Sundararajah et al.'s [5, 27] test data are only for thin channel sections. Hence, the developed FE models were again validated using Young and Hancock's [24] test data to ensure accurate predictions for thick channel sections. The comparison showed that the mean value of ratios of Young and Hancock's [24] tests to FEA predictions is 0.97 , with COV value of 0.06 , as shown in Table 2.

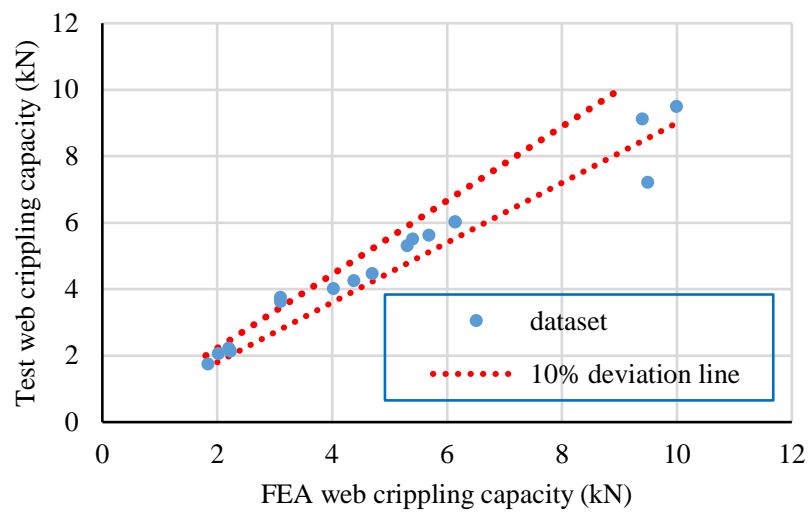

Fig. 6 Validation of lipped channel sections [5, 26]

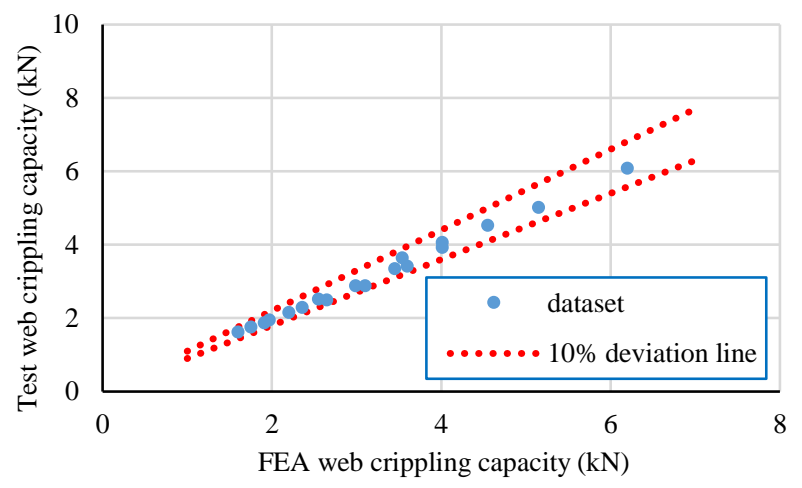

Fig. 7 Validation of unlipped channel sections [5, 27]

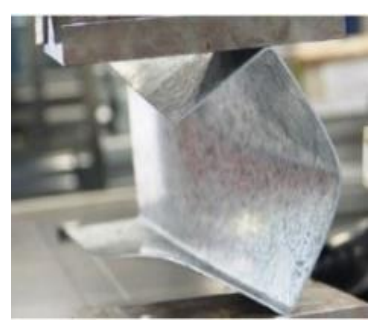

(a) Test [5]

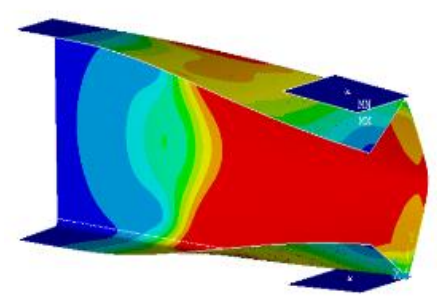

(b) FEA
Fig. 8 Failure mode comparison for without hole section
Finally, the developed FE models of lipped channels without and with web openings were validated using Uzzaman et al.'s [11-13]'s test data. Table 3 shows the comparison of Uzzaman et al.'s [11-13] test data to FEA predictions without web openings. The comparison showed that the mean value of ratios of the test to FEA predictions of lipped channels without web opening are 1.01 with $\mathrm{COV}$ value of 0.04

Table 2

Validation of Young and Hancock's [24] test data

\begin{tabular}{ccccc}
\hline $\begin{array}{c}\text { Unlipped channel } \\
\text { section }\end{array}$ & $N(\mathrm{~mm})$ & $L(\mathrm{~mm})$ & $\begin{array}{c}\text { FEA value } \\
(\mathrm{kN})\end{array}$ & Test/FEA \\
\hline $75-40-4$ & 20.0 & 113.6 & 19.8 & 0.92 \\
$75-40-4$ & 40.0 & 152.0 & 23.8 & 0.93 \\
$100-50-4$ & 25.0 & 175.0 & 21.5 & 1.05 \\
$100-50-4$ & 50.0 & 200.2 & 25.6 & 0.97 \\
$125-65-4$ & 32.5 & 219.8 & 22.6 & 1.04 \\
$125-65-4$ & 65.0 & 252.5 & 27.5 & 1.03 \\
$200-75-5$ & 37.5 & 336.9 & 33.5 & 0.93 \\
$200-75-5$ & 75.0 & 375.3 & 38.9 & 1.03 \\
$250-90-6$ & 45.0 & 421.0 & 51.0 & 0.92 \\
$250-90-6$ & 90.0 & 465.1 & 55.0 & 0.92 \\
$300-90-6$ & 45.0 & 495.2 & 44.7 & 1.02 \\
$300-90-6$ & 90.0 & 539.6 & 54.5 & 0.91 \\
& Mean & & & 0.97 \\
& COV & & & 0.06 \\
\hline
\end{tabular}

Table 3

Validation of Uzzaman et al.'s [11-13] test data

\begin{tabular}{ccccc}
\hline $\begin{array}{c}\text { Lipped channel } \\
\text { section }\end{array}$ & $\mathrm{N}(\mathrm{mm})$ & $L(\mathrm{~mm})$ & $\begin{array}{c}\text { FEA value } \\
(\mathrm{kN})\end{array}$ & Test/FEA \\
\hline $142-60-13$ & 90 & 337.5 & 2.20 & 1.00 \\
$142-60-13$ & 120 & 350.0 & 2.50 & 0.94 \\
$172-65-13$ & 120 & 400.0 & 2.31 & 1.03 \\
$202-65-13$ & 100 & 410.0 & 2.78 & 1.04 \\
$202-65-13$ & 120 & 425.0 & 2.60 & 1.04 \\
$202-65-13$ & 150 & 450.0 & 2.74 & 1.04 \\
$202-65-14$ & 150 & 460.0 & 3.10 & 1.03 \\
$202-65-15$ & 200 & 510.0 & 3.78 & 1.03 \\
$262-65-13$ & 120 & 525.0 & 2.71 & 0.94 \\
$262-65-13$ & 150 & 550.0 & 2.89 & 0.98 \\
& Mean & & & 1.01 \\
& COV & & & 0.04 \\
\hline
\end{tabular}

Note: $N$ - bearing length, $L$ - specimen length

Figs. 9 and 10 show the comparison of FE results of lipped channels with centred beneath and offset web openings, respectively, with Uzzaman et al.[1113]'s experimental studies. The comparison showed that mean values of ratios of the tests to FEA predictions of lipped channel sections with centred beneath and offset web openings are 0.97 and 1.10 , respectively with corresponding $\mathrm{COV}$ values of 0.03 and 0.06 . Failure modes obtained from FE models are agreed with Uzzaman et al.'s [11-13] experimental failure modes with increasing $a / h$ ratio from 0 to 0.6 , as shown in Fig. 11 . Table 4 shows a summary of finite element validation. This validation procedure showed that the developed web crippling FE models without and with web opening under ETF load case predicted test web crippling capacities accurately. Therefore, these FE models can be used for parametric study confidently.

A detailed parametric study is undertaken using validated FE models to improve understanding of the web crippling behaviour of unlipped channels without and with web openings under ETF load case. The parametric study considers the effects of different parameters such as section thickness, material strength, web slenderness ratio and bearing length on the web crippling of unlipped chan- 
nels without web openings. Additionally, the effect of centred beneath and offset web opening was investigated by varying the ratios of the diameter of web opening to a height of straight part of the web of the section $(a / h)$ and distance from bearing plate to clear height of the web $(x / h)$. Totally $186 \mathrm{FE}$ models with centred beneath web openings, 540 offset web openings, and 72 FE models without web opening were developed and analysed in this parametric study. The predictions of existing web crippling design equations for unlipped channel sections without web opening were checked, and new reduction factor equation is proposed based on the obtained web crippling data.

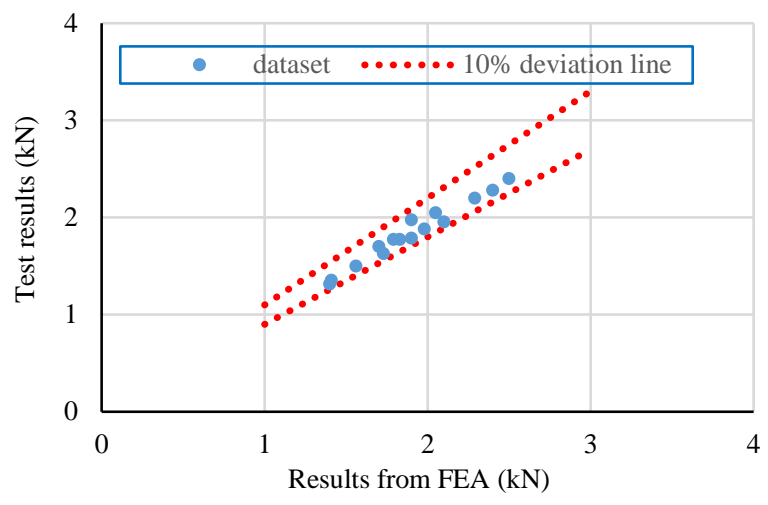

Fig. 9 Validation results of Uzzaman et al.'s [11-13] test with openings

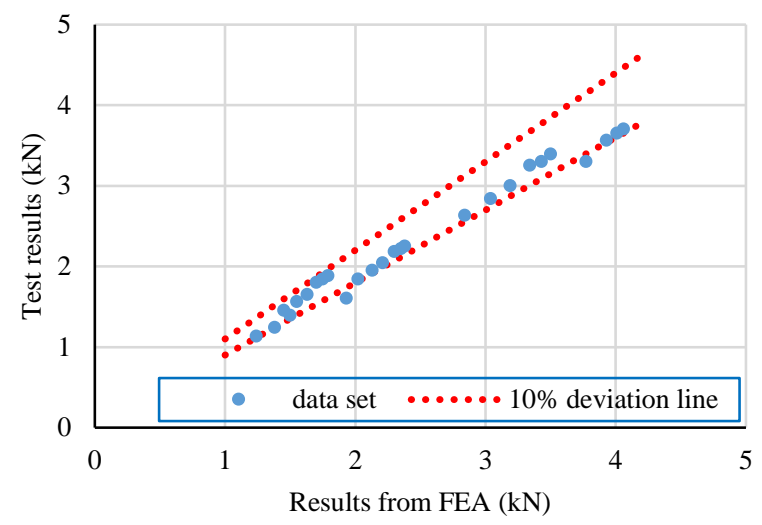

Fig. 10 Validation results of Uzzaman et al.'s $[12,13]$ with offset hole sections

Table 4

Summary of past research studies validations

\begin{tabular}{ccccc}
\hline Section & Researcher & $\begin{array}{c}\text { No of mod- } \\
\text { els }\end{array}$ & Mean & COV \\
\hline \multirow{2}{*}{ Without web opening } & & & \\
Unlipped channel & Young and Hancock [24] & 12 & 0.97 & 0.06 \\
& Sundararajah et al. [5, 27] & 18 & 0.98 & 0.03 \\
& Uzzaman et al. [11-13] & 10 & 1.01 & 0.04 \\
Lipped channel & Sundararajah et al. [5, 27] & 18 & 1.00 & 0.09 \\
& With web opening & & & \\
Lipped channel- & Uzzaman et al. [11-13] & 15 & 0.97 & 0.03 \\
centred beneath & & & & \\
Lipped channel- & Uzzaman et al. [11-13] & 26 & 1.1 & 0.06 \\
offset & & & & \\
& Overall
\end{tabular}

\section{Results and discussion}

\subsection{Predictions compared with existing design equations}

The capacities of unlipped channels with web openings under ETF load case obtained from parametric numerical studies were compared with the available design equation for web crippling such as (i) unified design equation with coefficients of AISI S100 [18] and AS/NZS 4600 [19], the same above mentioned equation but with modified coefficients suggested by Gunalan and Mahendran $[25,26]$ and semi-empirical equation proposed by Young and Hancock [24].

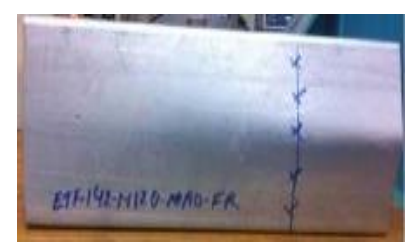

$a / h$ ratio 0

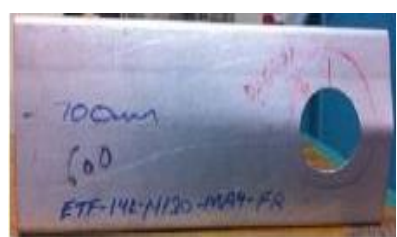

$a / h$ ratio 0.4

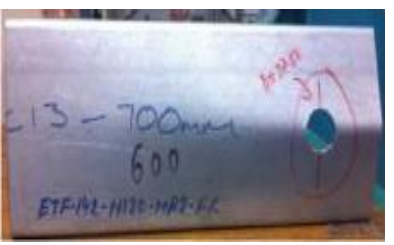

$a / h$ ratio 0.2

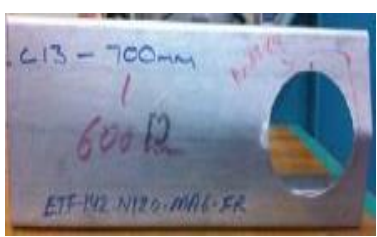

$a / h$ ratio 0.6

(a) Uzzaman et al.'s [11-13] test failure

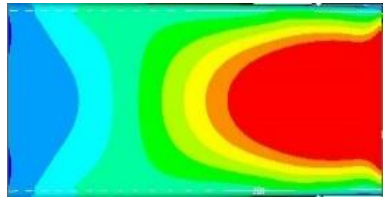

$a / h$ ratio 0

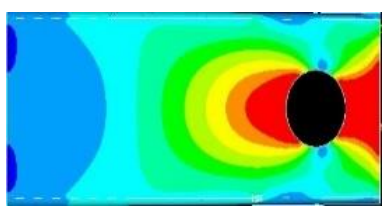

$a / h$ ratio 0.4

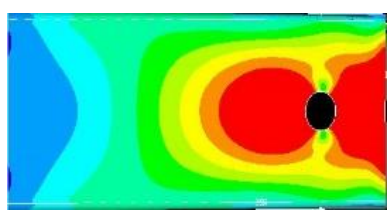

$a / h$ ratio 0.2

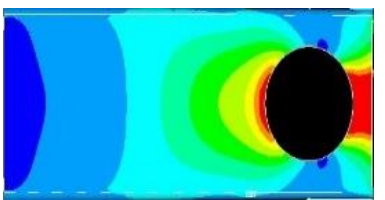

$a / h$ ratio 0.6 (b) FEA failure modes

Fig. 11 Failure mode comparisons of with and without web opening sections

(i) Fig. 12 compared the capacity predictions of unlipped channels using numerical models under web crippling without web-openings with estimated web crippling capacities based on unified design equation (Equation 1) with available coefficients in AISI S100 [18] and AS/NZS 4600 [19]. The comparison indicated that the mean value of the ratio of predictions from FE models to unified design equation with coefficients available in AISI S100 [18] and AS/NZS 4600 [19] is 0.91 while the COV of the comparison is 0.22 for unlipped channels with unfastened supports under ETF load case. The comparison showed that the predictions of the unified design equation with current existing coefficients are slightly conservative.

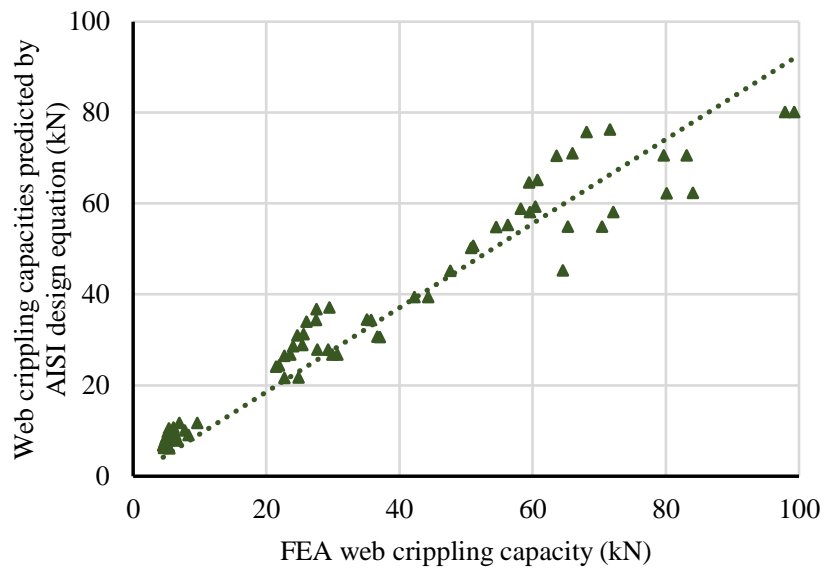

Fig. 12 Comparison of FEA results with predictions using unified web crippling equation based on AISI S100 [18] coefficients

(ii) Gunalan and Mahendran [25] also reported that capacity predictions of 
current design equations with available coefficients in AISI S100 [18] and AS/NZS 4600 [19] for unfastened support unlipped channels under all four load cases are unconservative. The observation mentioned above is similar to Fig. 13. Therefore, they proposed new coefficients only to the current unified design equation (Equation 1) as listed in Table 5. In this study, the FEA capacity predictions of unlipped channels observed from numerical models were compared with the capacity estimation of unified design equation using the proposed coefficients by Gunalan and Mahendran [25]. The comparison indicated that the mean value of the ratio of predictions from FE models to unified design equation with coefficients proposed by Gunalan and Mahendran [25] is 1.17 while the $\mathrm{COV}$ of the comparison is 0.12 for unlipped channels with unfastened supports under ETF load case. This comparison showed that the capacity predictions of the unified design equation with proposed coefficient by Gunalan and Mahendran [25] is conservative for unlipped channels without web openings under ETF load case. Hence these coefficients can be used with the unified design equation to estimate web crippling capacity of unlipped channels under ETF loading. However, the new coefficients can be proposed to improve the prediction accuracy further.

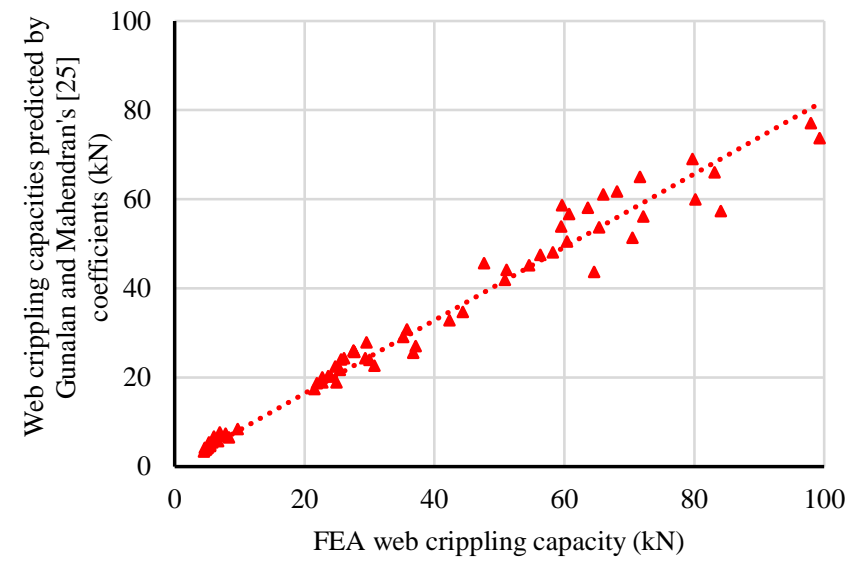

Fig. 13 Comparison of FEA results with predictions using unified web crippling equation based on Gunalan and Mahendran's [25] coefficients

Table 5

Proposed web crippling coefficient for unlipped channels

\begin{tabular}{lllllll}
\hline Equation & $\mathrm{C}$ & $\mathrm{C}_{\mathrm{r}}$ & $\mathrm{C}_{\mathrm{l}}$ & $\mathrm{C}_{\mathrm{w}}$ & Mean & $\mathrm{COV}$ \\
\hline AS/NZS 4600 [19] & 2.00 & 0.11 & 0.37 & 0.01 & 0.91 & 0.22 \\
Gunalan and Mahendren [25] & 3.05 & 0.19 & 0.26 & 0.05 & 1.17 & 0.12 \\
Proposed & 3.50 & 0.19 & 0.27 & 0.05 & 1.00 & 0.10 \\
\hline
\end{tabular}

(iii) Young and Hancock [24] developed a semi-empirical equation as shown in Equations 6a to 6e, to predict the web crippling capacities of unlipped channels without web-openings under ETF load case. This equation was developed using a combination of theoretical and empirical analysis and had a critical limitation which is only applicable to stocky unlipped channels, where slenderness of the web is less than 45 .

$P_{p m}=\frac{{ }^{M}{ }_{p} N_{m}}{r}\left[1.44-0.0133\left(\frac{h}{t}\right)\right]$

$M_{p}=\frac{f_{y} t^{2}}{4}$

$r=r_{i}+\frac{t}{2}$

$N_{m}=N+0.5 d, \quad N+0.3 d$ for EOF and ETF load case

$N_{m}=N+1.3 d, N+1.40 d$ for IOF and ITF load case

Where $P_{p m}$ is the capacity prediction of web crippling based on plastic mechanism model, $M_{p}$ - plastic moment per unit length, $r$ and $r_{i}$ are bent radii about centreline and internal dimensions, respectively, $h$ - the height of the straight portion of the web of unlipped channels, $d$ - web overall depth, $N$ - the bearing length
Fig. 14 compared the capacity predictions of unlipped channels using numerical models under web crippling without web-openings with estimated capacity values using the equation proposed by Young and Hancock [24]. The comparison indicated that the mean value of the ratio of predictions from FE models to the capacity estimation by Young and Hancock's [24] semi-empirical equation is 1.00 while the $\mathrm{COV}$ of the comparison is 0.14 for unlipped channels with unfastened supports under ETF load case. The comparison mentioned above showed that the proposed equation by Young and Hancock [24] can be still used to estimate the web crippling capacities of unlipped channels without web openings under ETF load case.

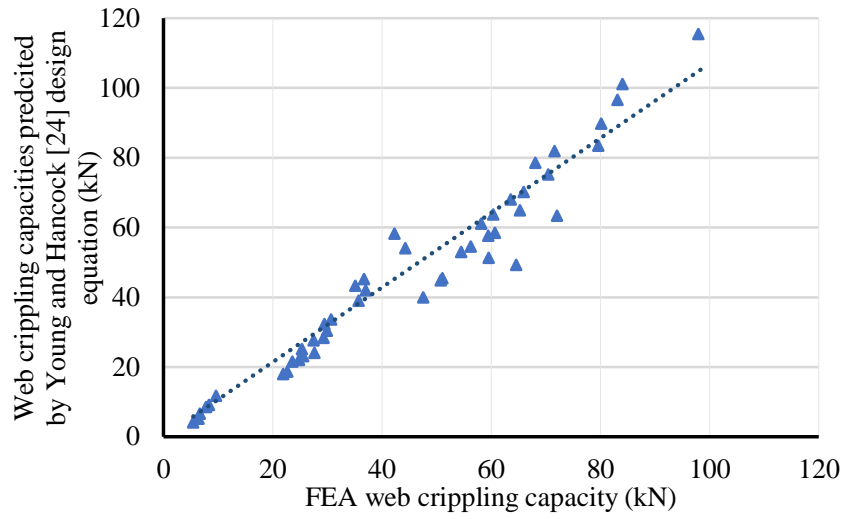

Fig. 14 Comparison of FEA results with predictions using Young and Hancock's [24] design equation

\subsection{Improved design equation}

As discussed in the above section (Section 6.1), currently available coefficients with unified design equation (Equation 1) predicted the capacities of unlipped channels without web-openings under web crippling for ETF load case unconservatively. Therefore, these currently available coefficients cannot be used to estimate failure loads of unlipped channels when they used as bearers and joists in construction. Although predicted capacities using the semi-empirical equation by Young and Hancock [24] agreed with predictions by FEA predicted capacities, their equation has a significant limitation, which restricts the applicability of their equation only to stocky unlipped channels, where the slenderness of the web is less than 45 . The unified design equation (equation 1) with proposed improved coefficients by Gunalan and Mahendarn [25] predicted the capacities of unlipped channels without web-openings under ETF load case, conservatively. However, their coefficients were proposed based on 28 test results, and hence the proposed coefficients by them have fine-tuned form this study and given in Table 5. Fig. 15 compared the capacity predictions of unlipped channels using numerical models under web crippling without web-openings with estimated capacity values using the unified design equation with proposed coefficients as listed in Table 5. The comparison indicated that the mean value of the ratio of predictions from FE models to unified design equation with coefficients proposed from this study is 1.00 while the COV of the comparison is 0.10 for unlipped channels with unfastened supports under ETF load case. It is shown that the proposed coefficients agree well with the numerical results. The coefficient only applies for $\mathrm{h} / \mathrm{t} \leq 115, \mathrm{~N} / \mathrm{t} \leq 75, \mathrm{~N} / \mathrm{h} \leq 1.9, \mathrm{a} / \mathrm{h} \leq 0.8$ and $\Theta$ $=90$.

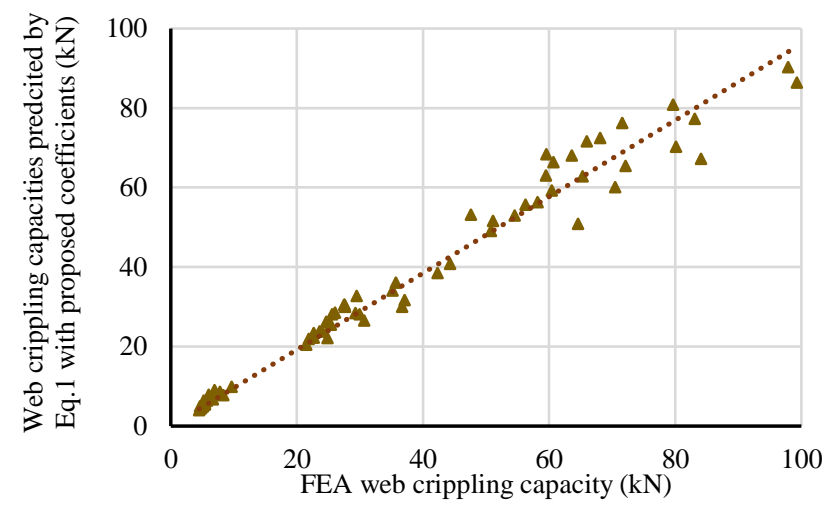

Fig. 15 Comparison of FEA results with predictions using unified web crippling equation based on Authors proposed coefficients 


\subsection{Capacity reduction due to web opening}

As discussed earlier, the introduction of the openings at the web of unlipped channels reduces the resisting area of the concentrated loads and hence vulnerability chances of web crippling increase further for unlipped channels under concentrated loads. Typically, web crippling failure initiates at the free edges of channel sections under ETF load cases. However, the failure mechanism is changed with the introduction of the web opening, as shown in Fig. 16. As shown in Fig.16, in stage - 01 and stage - 02, web crippling failure is initiated near to the web opening, and it proliferates towards the free edge of the web compared to another side. After that in stage - 03, it extends to another side of the web section due to the load increment. Beyond that point in the ultimate stage - 04 , the web of the section is crippled. Due to above-mention reason, web crippling failure of unlipped channels with web openings under ETF load case should be investigated.
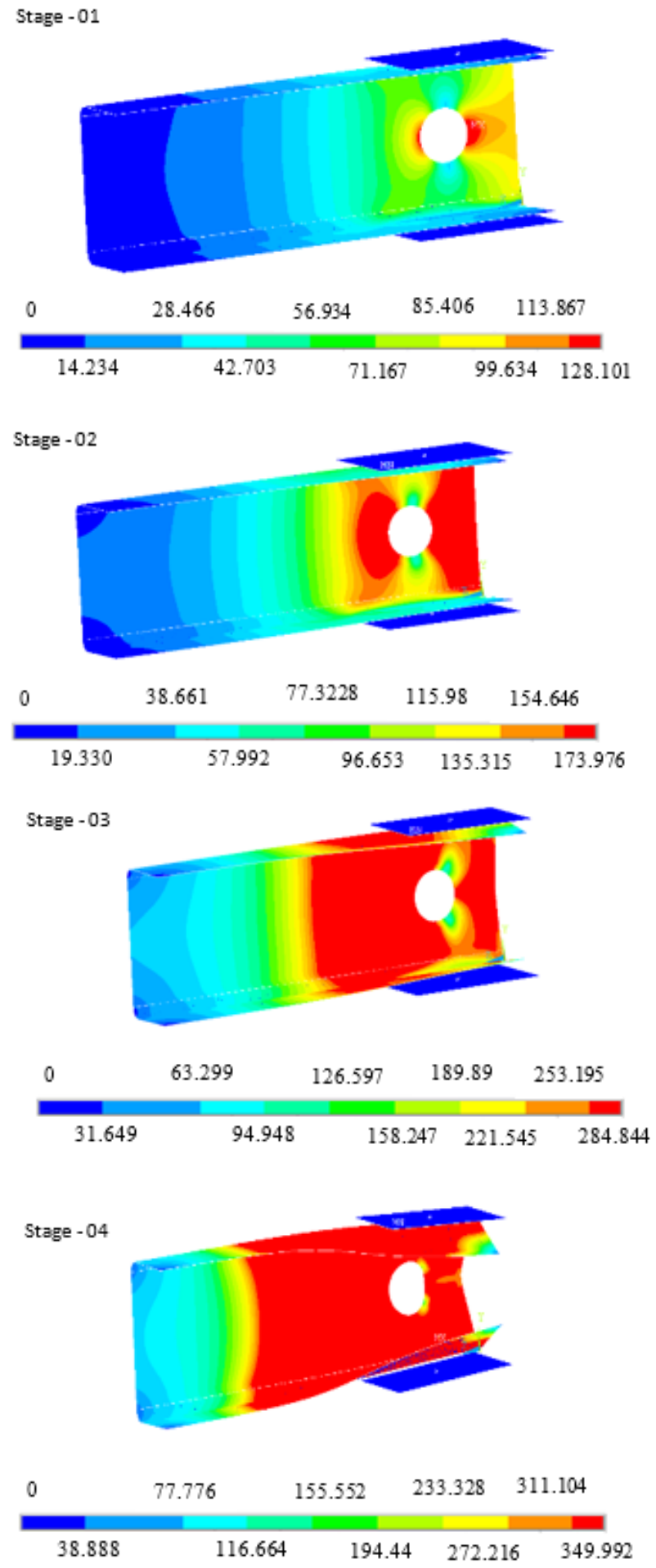

Fig. 16 Effect of web hole in the failure mechanism of unlipped channel sec-

$$
\text { tion }
$$

Altogether, 186 and 540 numerical models of unlipped channels under ETF load case with two types of circular web openings such as (i) centred beneath and (ii) offset, respectively to investigate the effect of these openings on the web crippling capacity. The purpose of the study is also to identify the influencing parameters and to determine the reduction of web crippling capacity. The study indicated that two critical ratios such as (i) ratio of the diameter of the circular web opening to the height of the straight portion of the web $(a / h)$ of unlipped channels and (ii) bearing length to the height of the straight portion of the web $(N / h)$ of unlipped channels, dominated the reduction of web crippling of unlipped channels with centred beneath web openings. Similarly, another two critical ratios such as (i) the ratio of the nearest distance of the circular web opening to the edge of the bearing plate $(x / h)$ and (ii) bearing length to the height of the straight portion of the web of unlipped channels $(N / h)$ dominated the reduction of web crippling of unlipped channels with offset web openings. These observations are similar to past research outcomes. The effect of above-mentioned ratios on the web crippling capacity reduction of unlipped channels was investigated as discussed below.

The capacity reduction and its percentages of two unlipped channels such as $100 \times 50 \times 4$ and $150 \times 75 \times 2$, subjected to concentrated load via 100 and 150 $\mathrm{mm}$ bearing plates, respectively with varying ratio of the diameter of web opening to the height of straight web portion of the web of the channel $(a / h)$ from 0 to 0.8 were investigated and reported in Table 6 .

Table 6

Capacity reduction due to web hole

\begin{tabular}{cccc}
\hline $\begin{array}{c}\text { Bearing length } \\
N(\mathrm{~mm})\end{array}$ & alh ratio & $\begin{array}{c}\text { FEA value } \\
(\mathrm{kN})\end{array}$ & Reduction $\%$ \\
\hline $100 \times 50 \times 4$, specimen length $300 \mathrm{~mm}$ & \\
100 & 0.0 & 30.0 & - \\
100 & 0.2 & 27.1 & 9.7 \\
100 & 0.4 & 23.6 & 21.3 \\
100 & 0.6 & 20.4 & 32.0 \\
& 0.8 & 17.5 & 41.7 \\
150 & $150 \times 75 \times 2$, specimen length $450 \mathrm{~mm}$ & - \\
150 & 0.0 & 6.1 & 8.2 \\
150 & 0.2 & 5.6 & 19.7 \\
150 & 0.4 & 4.9 & 31.1 \\
150 & 0.6 & 4.2 & 40.1 \\
\hline
\end{tabular}

As listed in Table 6, the capacity reduction of $100 \times 50 \times 4$ unlipped channels due to web opening underneath the bearing plate subjected to the concentrated load via $100 \mathrm{~mm}$ bearing plate is $9.7,21.3,32.0$ and 41.7 percentages with the variation of the ratio of the diameter of circular web opening to the height of the straight portion of the web of the section $(a / h)$ from 0 to 0.8 in steps of 0.2 . However, the observed reductions for $150 \times 75 \times 2$ unlipped channels with circular web openings subjected to concentrated load via $150 \mathrm{~mm}$ are 8.2, 19.7, 31.1 and 40.1 percentages with the above $(a / h)$ variation. The above observation showed the capacity reduction of web crippling depends on the bearing lengths in addition to different steel profiles. As discussed, although the reduction percentages varied for different steel profiles, the capacity reduction of web crippling for unlipped channels with circular centred beneath web opening almost linearly increases with the ratio of the diameter of circular web opening to the height of the straight portion of the web of unlipped channels as shown in Fig. 17. Fig. 17 showed that above mentioned $a / h$ ratio is one of the critical parameters, dominates the web crippling reduction of unlipped channels with centred beneath web openings. 


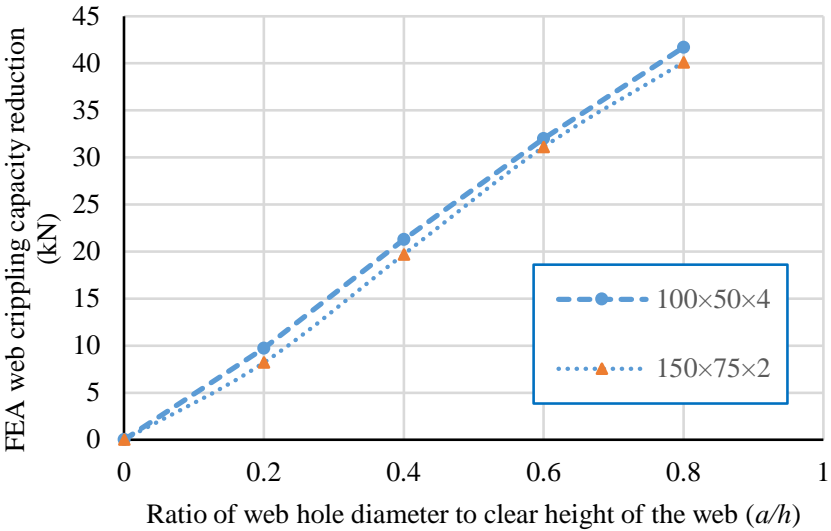

Fig. 17 Effect of web opening diameter to clear height of the web on web crippling capacity reduction

The effect of different bearing lengths on the web crippling capacity of unlipped channels with circular centred beneath web opening under ETF load case was investigated using two test samples such as (i) $100 \times 50 \times 4 \mathrm{~mm}$ unlipped channels concentrically loaded via bearing lengths of 50,100 and $150 \mathrm{~mm}$ and (ii) $200 \times 75 \times 4 \mathrm{~mm}$ unlipped channels concentrically loaded via bearing lengths of 90,120 and $150 \mathrm{~mm}$. The effect of bearing plate lengths on web crippling capacity with increasing web opening diameter to height of the straight portion of the web $(a / h)$ values for the section are shown in Fig. 18(a) and (b), respectively. As shown in Figs. 18(a) and 18(b), the ultimate capacities of unlipped channels with web openings under web crippling for ETF load case increases linearly with increasing bearing lengths for both considered sections. However, the increment percentage is different for both sections. The web crippling capacity increases by $24,26,30$ and 34 percentages with the increasing a/h ratio values of $0.2,0.4$ and 0.6 for $100 \times 50 \times 4 \mathrm{~mm}$ unlipped channel subjected to concentrated load via $150 \mathrm{~mm}$ bearing plate compared to $100 \mathrm{~mm}$ bearing plate. Similarly, the web crippling capacity increases by $13 \%$ for all a/h values for $200 \times 75 \times 4 \mathrm{~mm}$ unlipped channel subjected to concentrated load via $150 \mathrm{~mm}$ compared to $120 \mathrm{~mm}$. Fig. 18 displayed that the capacity reduction of unlipped channels depends on the bearing length also an addition to the ratio of the diameter of web opening to the height of the straight portion of the web of unlipped channels. Therefore, bearing length effect also must be included in the reduction factor. Therefore, the web crippling reduction factor for centred beneath web openings was developed using above mentioned two parameters such as (i) diameter of the circular web opening to the height of the straight portion of the web and (ii) bearing length to the height of the straight portion of the web.

This study also investigates the effects of circular web openings located away the concentrated loads (circular offset) on the capacity of unlipped channels under web crippling, and the observed results are displayed in Fig. 19. Fig. 19 portrayed the variation of web crippling capacity of unlipped channels with the increasing ratio of the near web opening distance from the edge of bearing plate to the height of the straight part of the web $(x / h)$. The capacities of some unlipped channels under web crippling showed increment by $15 \%$. In comparison, others showed $10 \%$ increment only with the variation of the ratio of the near web opening distance from the edge of bearing plate to the height of the straight part of the web $(x / h)$ from 0 to 0.6 . Based on the observation, another reduction factor should be proposed for offset circular web openings based on the ratios of the ratio of the near web opening distance from the bearing plate edge to the height of the straight web part $(x / h)$ and diameter of circular web opening to the height of the straight web part $(a / h)$.

\subsection{Proposed strength reduction factor}

The reduction due to web openings both located underneath and away from the bearing plate was determined by comparing the FE predicted capacity of unlipped channels with and without opening. Then the ratio of capacity reduction to the web crippling capacity of unlipped channels without web openings was determined, and this ratio was the capacity reduction factor. Based on conducted parametric study, the capacity reductions of unlipped channels with web openings underneath the bearing plates under ETF load case showed the linear variation trend for the two ratios such as: (i) the capacity reducing with the increasing ratio of the diameter of circular web opening to the height of straight part of the web $(a / h)$ and (ii) the capacity increases with the ratio of the bearing length to the height of the straight part of the web $(N / h)$. Based on the above observation and using all determined capacity reduction values from the parametric study, an equation for the reduction factor is developed using bivariate linear regression analysis in terms of above two ratios as shown in Equation $7 \mathrm{a}$.
$R_{b}=0.95-0.6(a / h)+0.06(N / h)$

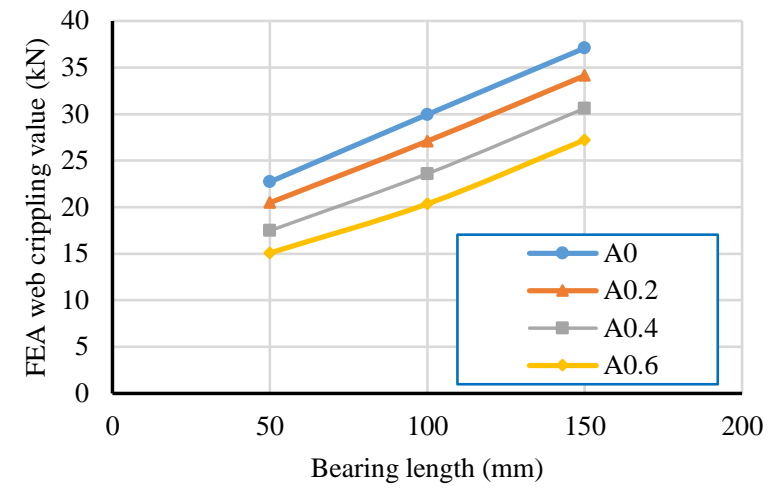

(a) $100 \times 50 \times 4 \mathrm{~mm}$ unlipped channel

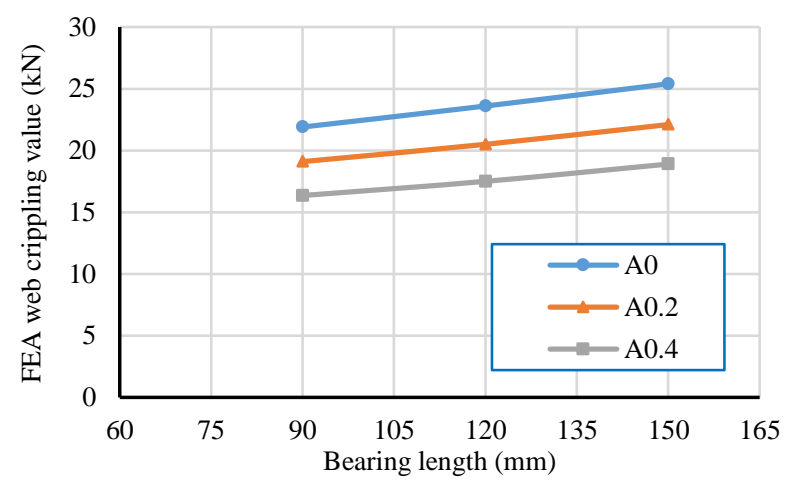

(b) $200 \times 75 \times 4 \mathrm{~mm}$ unlipped channe

Fig. 18 Effect of bearing length on web crippling capacity of unlipped channels

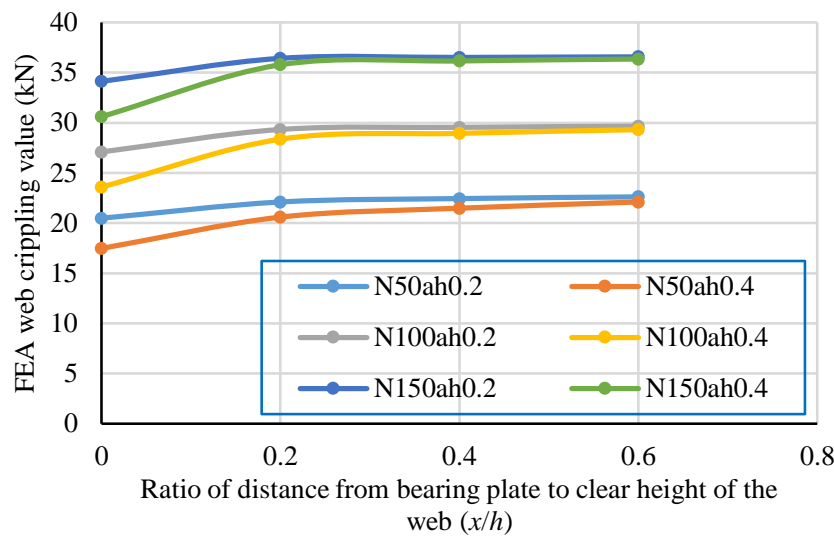

Fig. 19 Web crippling capacity variation with location of opening

Similarly, the capacity reductions of unlipped channels with web openings located away from the bearing plates (offset) showed a linear variation trend with two ratios such as (i) the capacity reducing with the increasing ratio of the diameter of circular web opening to the height of straight part of the web $(a / h)$ and (ii) the capacity increases with the ratio of the near web opening distance from the edge of bearing plate to the height of the straight part of the web $(x / h)$. Based on the above observation and using all determined capacity reduction values, an equation for the reduction factor is developed using bivariate linear regression analysis in terms of the above two ratios, as shown in Equation $7 \mathrm{~b}$.

$R_{b}=0.98-0.25(a / h)+0.17(x / h)$

The limits for the reduction factor Equations $7 \mathrm{a}$ and $7 \mathrm{~b}$ are $h / t_{w} \leq 115, N / t_{w}$ $\leq 75, N / h \leq 1.9, \mathrm{a} / \mathrm{h} \leq 0.8$ and $\Theta=90^{\circ}$.

Figs. 20 and 21 compared the predictions of reduction factors determined using the above developed two equations for unlipped channels with circular centred beneath and offset web openings, respectively for ETF load case with calculated reduction factors using capacity values of unlipped channels with and without web openings. The mean value of the ratio of predicted reduction 
factors using the proposed equation to reduction factors determined using FE capacities are 0.99 and 1.00 for centred beneath and offset web openings, respectively with the corresponding $\mathrm{COV}$ values of 0.05 and 0.11 for unlipped channels with unfastened supports for ETF load case. Therefore, the proposed capacity reduction factor equations with the unified design equation (Equation 1) can be used to predict the capacities of unlipped channels with web openings with unfastened supports under ETF load case.

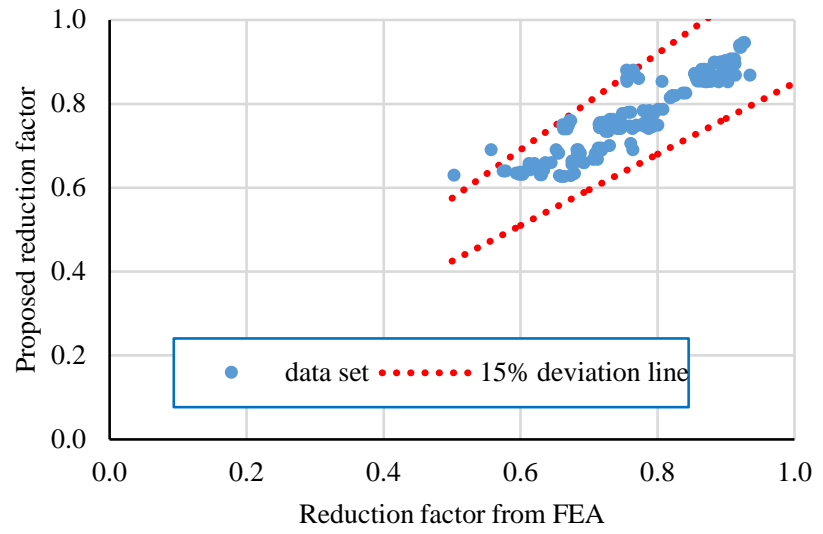

Fig. 20 Comparison of reduction factor obtained using proposed equation for centred beneath and FEA

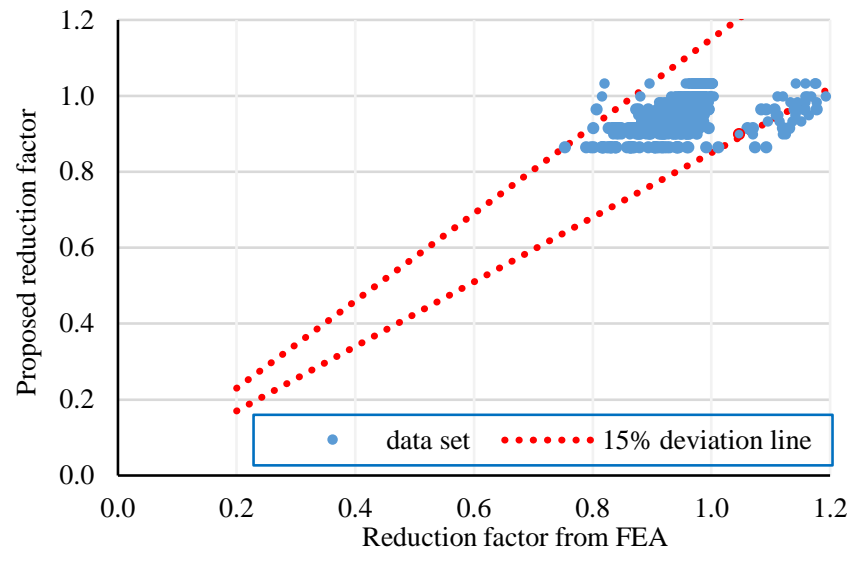

Fig. 21 Comparison of reduction factor obtained using proposed equation for offset and FEA

The capacity reduction factor is applied to adjust the prediction for safe design. The North American specification for the design of cold-formed steel structural members [20] recommends the following equation to calculate the capacity reduction factor $\left(\varphi_{\mathrm{w}}\right)$.

$\phi_{w}=C M_{m} F_{m} P_{m} e^{-x}$

$x=\beta_{0} \sqrt{V_{M}{ }^{2}+V_{F}{ }^{2}+C_{P} V_{P}{ }^{2}+V_{Q}{ }^{2}}$

In Eq. 10, C is equal to 1.521 from AISI S100. The statistical parameters are obtained from AISI S100 for web crippling strength, where $\mathrm{Mm}=1.1, \mathrm{Fm}$ $=1.0, \mathrm{VM}=0.1$ and $\mathrm{VF}=0.05$. The parameters $\mathrm{Pm}$ and $\mathrm{Vp}$ are the mean and the coefficient of variation of the tested to predicted load ratio. The statistical parameter VQ is the coefficient of variation of load effects and depends on the dead load to live load ratio (D/L). It is given as 0.21 in AISI S100 [18]. The parameter $\mathrm{Cp}$ is a correction factor for the small number of tests and is given by $; \mathrm{n}$ is the number of tests; $\mathrm{m}$ is the degree of freedom $=\mathrm{n}-1$. The values of $\mathrm{Pm}$ and $\mathrm{Vp}$, in this case, are 0.990 and 0.049 for centred beneath and 1.00 and 0.11 for offset as well, which are based on the FEA/Proposed ratios. Using these values, Eq. 10 gives a capacity reduction $\left(\varphi_{\mathrm{W}}\right)$ of 0.90 and 0.87 for centred beneath and offset respectively for target reliability index of 2.5 .

\section{Conclusion}

This article presented the details of numerical investigation of the effects of circular web openings on the web crippling performance of unfastened unlipped channels under ETF load case. The two types of web openings such as opening directly beneath the concentrated load (centred beneath) and an opening located away from the concentrated load (offset) were considered. Numerical models of lipped and unlipped channels without web openings were developed and validated in ANSYS software using existing five test data set in the literature to create more accurate FE model without errors due to practical differences. Based on the validated FE models, the behaviour of unlipped channels without web openings was first investigated and compared with predictions using available design equations. The capacity predictions of unlipped channels without web opening under ETF load case using unified design equation with current web crippling coefficients in AISI S100 and AS/NZS 4600 were unconservative while the suggested design equations by Young and Hancock [24] and Gunalan and Mahendran [25] were conservative and can be used. The improved coefficients were proposed to the current unified web crippling design equations to improve the capacity prediction accuracy of unfastened unlipped channels without web openings under ETF load case. The numerical models of unlipped channels with web circular openings underneath the bearing plate and away from the bearing plate were developed and validated using two existing test data. The validated numerical models were then used to investigate the capacity reduction of unfastened unlipped channels subjected to web crippling with circular web openings underneath and away from the concentrated loads for ETF load case. Each two ratios were identified as critical ratios for capacity reduction of unlipped channels with web openings underneath and away from the bearing plates such as (i) the diameter of circular web opening to the height of straight part of the web $(a / h)$ and bearing length to the height of straight part of the web $(N / h)$ for web openings directly underneath the load plates while (ii) the diameter of circular web opening to the height of straight part of the web $(a / h)$ and the web opening near distance to the edge of the bearing plate to the height of the straight web part $(x / h)$. Based on the parametric study, two separate reduction factor equations were developed for unlipped channels with web openings directly underneath and located away from the bearing plates, respectively based on above-identified two critical ratios under ETF load case. The proposed reduction factors can be used with the unified design equation (Equation 1) with proposed improved four coefficients from this study can be used to estimate failure loads of unlipped channels with both types of web openings under ETF load case.

\section{References}

[1] Hetrakul, N., and Yu, W.W. (1978), Structural behaviour of beam webs subjected to web crippling and a combination of web crippling and bending, Final Report, Civil Engineering Study 78-4, University of Missouri-Rolla, Rolla, Missouri, USA

[2] Gerges, R.R. and Schuster, R.M. (1998), Web Crippling of single web cold-formed stee members subjected to end-one-flange loading, Proc. of Fourth International Specialty Conference on Cold-formed Steel Structures, St. Louis, Missouri, USA.

[3] Beshara, B. and Schuster, R.M. (2000), Web crippling of cold-formed steel C and Z sections, Proc. of 15th International Speciality Conference on Cold-Formed Steel Structures, St.Louis, Missouri, U.S.A.

[4] Macdonald, M., Heiyantuduwa, M.A., Koteko, M. and Rhodes, J. (2011), Web crippling behaviour of thin-walled lipped channel beams. Thin-Walled Structures, 49: 682-690.

[5] Sundarajah, L., Mahendran, M. and Keerthan, P. (2017), New design rules for lipped channel beams subject to web crippling under two-flange load cases, Thin-Walled Structures, 2017; 119: 421-437

[6] Yu, W.W. and Davis, C.S., Cold-formed steel members with perforated elements, Journal of the Structural Division, 1973; 99: 2061-2077.

[7] Sivakumaran, K.S. and Zielonka, K.M., Web crippling strength of thin-walled steel member with web opening, Thin-Walled Structures, 1989; 8: 295-319.

[8] Langan, J.E., LaBoube, R.A. and Yu, W.W., Structural behavior of perforated web element of cold-formed steel flexural members subjected to web crippling and a combination of web crippling and bending, Final report, Civil Engineering Study 94-3, Cold-Formed Steel Series, Rolla, MO: University of Missouri- Rolla; 1994.

[9] LaBoube, R.A., Yu, W., Deshmukh, S. and Uphoff, C.A. (1999), Crippling capacity of web elements with openings, Journal of Structural Engineering, 1999; 125(2): 137-141.

[10] Uzzaman, A., Lim, J.B.P., Nash, D., Rhodes, J. and Young, B., Web crippling behaviour of cold-formed steel channel sections with offset web holes subjected to interior-two-flange loading, Thin-Walled Structures, 2012; 50: 76-86.

[11] Uzzaman, A., Lim, J.B.P., Nash, D., Rhodes, J. and Young, B., Cold-formed steel sections with web openings subjected to web crippling under two-flange loading conditions-part I: Tests and finite element analysis. Thin-Walled Struct 2012;56:38-48.

[12] Uzzaman, A., Lim, J.B.P., Nash, D., Rhodes, J. and Young, B., Cold-formed steel sections with web openings subjected to web crippling under two-flange loading conditions-part II: Parametric study and proposed design equations, Thin-Walled Structures, 2012; 56: 79-87.

[13] Uzzaman, A., Lim, J.B.P., Nash, D., Rhodes, J. and Young, B., Effect of offset web holes on webcrippling strength of cold-formed steel achannel sections under end-two-flange loading condition, Thin-Walled Structures, 2013; 65: 34-48.

[14] Lian, Y., Uzzaman, A., Lim, J.B.P., Abdelal, G., Nash, D. and Young, B. (2016), Effect of web holes on web crippling strength of cold-formed steel channel sections under end-oneflange loading condition - Part I: Tests and finite element analysis, Thin-Walled Structures, 2016; 107: 443-452.

[15] Lian, Y., Uzzaman, A., Lim, J.B.P., Abdelal, G., Nash, D. and Young, B. (2016), Effect of web holes on web crippling strength of cold-formed steel channel sections under end-oneflange loading condition - Part II: Parametric study and proposed design equations, Thin- 
Walled Structures, 2016; 107: 489-501.

[16] Lian, Y., Uzzaman, A., Lim, J.B.P., Abdelal, G., Nash, D. and Young, B. (2017), Web crippling behaviour of cold-formed steel channel sections with web holes subjected to interiorone-flange loading condition- Part I: Experimental and numerical investigation, Thin-Walled Structures, 2017; 111: 103-112.

[17] Lian, Y., Uzzaman, A., Lim, J.B.P., Abdelal, G., Nash, D. and Young, B. (2017), Web crippling behaviour of cold-formed steel channel sections with web holes subjected to interiorone-flange loading condition- Part II: Parametric study and proposed design equations. ThinWalled Structures, 2017; 114: 92-106.

[18] American Iron and Steel Institute (AISI), Specifications for the cold-formed steel structural members, cold-formed steel design manual, AISI S100, Washington DC, USA, 2017.

[19] Standards Australia/Standards New Zealand (SA), Australia/New Zealand Standard AS/NZS 4600 Cold-formed steel structures, Sydney, Australia, 2018

[20] Eurocode 3 Part 1.3 (ECS), Design of Steel Structures: Part 1.3: General Rules - Supplementary rules for cold-formed thin gauge members and sheeting, European Committee for Standardization, Brussels, Belgium, 2006.

[21] American Iron and Steel Institute, Standard test method for determining the web crippling strength of cold-formed steel beams, AISI S909, Washington DC, USA, 2017.

[22] Sivakumaran, K., Analysis of web crippling behaviour of cold-formed steel members, Comput. Struct. 32 (1989) 707-719.

[23] Winter, G. and Pian, R.H.J. (1946), Crushing Strength of Thin Steel Webs, Engineering Experiment, Bulletinno.35, Cornell University, New York, US

[24] Young, B. and Hancock, G., Design of cold-formed channels subjected to web crippling, Journal of Structural Engineering, 2001; 127: 1137-1144.

[25] Gunalan, S. and Mahendran, M. (2015), Web Crippling Tests of Cold-formed Unlipped Channel Sections under Two Flange Load Cases, Journal of Constructional Steel Research, Vol. 110, pp. 1-15

[26] Gunalan, S. and Mahendran, M. (2019), Experimental study of unlipped channel beams subject to web crippling under one flange load cases, Advanced Steel Construction, Vol. 15, pp. $165-172$.

[27] Sundararajah, L. Web Crippling Studies of Cold-formed Steel Channel Beams- Experiments, Numerical Analyses and Design Rules (Ph.D. thesis), Queensland University of Technology, Brisbane, Australia, 2016.

[28] Janarthanan, B., Mahendran, M. and Gunalan, S., Bearing capacity of cold-formed unlipped channels with restrained flanges under EOF and IOF load cases, Steel Construction, 2015; 8: 146-154.

[29] Janarthanan, B., Mahendran, M. and Gunalan, S., Numerical modelling of web crippling failures in cold-formed steel unlipped channel sections, Journal of Constructional Steel Research, 2019; 158: 486-501

[30] Janarthanan, B., Sundarajah, L., Mahendran, M., Keerthan, P. and Gunalan, S., Web crippling behaviour and design of cold-formed steel sections, Thin-Walled Structures, 2019; 140: 387403.

[31] Janarthanan, B. and Mahendran, M., Numerical study of cold-formed steel channel sections under combined web crippling and bending action, Thin-walled Structures, 2020,152

[32] Ren, W.X., Fang, S.E. and Young, B., Finite-element simulation and design of cold-formed steel channels subjected to web crippling, Journal of Structural Engineering, 2006; 132: 19671975 .

[33] Natario, P., Silvestre, N. and Camotim, D., Web crippling failure using quasi-static FE models Thin-Walled Structures, 2014; 84: 34-49.

[34] Ellilarasi, K. and Janarthanan, B., effect of web holes on the web crippling capacity of coldformed LiteSteel beams under End_Two-Flange load case, Structures, 2020; 25: 411-425.

[35] ANSYS Mechanical APDL Verification Manual, Release 15.0, 2013. MANUAL 